\title{
Middle East and North African Integration: through the lens of Non-Tariff Measures
}

\author{
Nicolas Péridy \\ Université de Toulon, Toulon, France \\ Ahmed Ghoneim \\ Cairo University, Cairo, Egypt
}

\begin{abstract}
Non-Tariff Measures (NTMs) have recently become a central issue for economists and policy makers. Based on a new database developed by the World Bank on five Middle East and North African(MENA) countries at a very detailed product level, this article provides calculations of the average tariff equivalents (AVEs) of NTMs in these countries. A second contribution is the development of an original empirical model with detailed trade costs. This makes it possible to provide the assessment of these NTMs impacts as well as other trade costs ones on the trade of goods in these countries. This analysis is also extended to the trade of 15 service sectors, through the use of the updated GTAP database. Results show that NTMs are very significant in the selected MENA countries. The model also shows that NTMs are significantly trade reducing in almost all MENA countries, especially Sanitary and Phytosanitary(SPS) measures. NTMs in services are also significantly trade reducing, especially in Maghreb countries. The study shows that not all NTMs must necessarily been reduced or removed, but the
\end{abstract}

\footnotetext{
* Corresponding Author: Nicolas Péridy; Léad, Université de Toulon, Avenue de l’Université, BP 20132, F-83957 La Garde cedex, France; Tel: +33 494142982, Fax: +33 494142165, E-mail: nicolas.peridy@univ-tln.fr.

Co-Author: Ahmed Ghoneim; Faculty of Economics and Political Science, Cairo University, Giza, Egypt; Tel: +20 233364499, Fax: +20 235711678, E-mail: aghoneim@gmx.de.
} 
ones which are particular trade-reducing must be paid particular attention. In addition, the governments should also progress toward either mutual recognition, or the adoption of international standards especially in relation to technical standards.

JEL Classifications: F13, F14, F15

Key words: Non-Tariff Measures, Middle East and North Africa, Average Tariff Equivalent, Gravity Models

\section{Introduction}

Non-Tariff Measures (NTMs) have recently become a central issue for economists and policy makers. This can be explained by the fact that despite the progressive reduction in tariffs though GATT/WTO and preferential schemes it is still not possible to fully eliminate trade barriers because of the existence of significant and often increasing NTMs. As a result, trade costs remain at high levels and may reduce economic gains in terms of trade, efficiency, and welfare.

This problem has led to an emerging interest on the part of economists in several respects (Carrère and de Melo, 2009 for a survey): The identification and classification of NTMs with the new UNCTAD classification (UNCTAD, 2009) updated in 2011; The measurement of NTMs, especially in terms of Ad Valorem Equivalents (AVEs); The calculation of the trade impact of NTMs; The extension of NTM measurement and impact on services and FDI; The effect of NTMs on domestic firms and industries.

Basically, it is expected that a better measurement and understanding of the economic effects of NTMs will be useful at the policy level, especially for future multilateral or regional agreements. With regard to Middle East North Africa(MENA) Arab countries ${ }^{1}$, there is still much to be done in this topic, although some international organizations have already started working on NTM identification, especially through a recent database developed by the World Bank (Augier and Péridy, 2010). However, there are still very few studies which have measured NTMs in terms of average equivalents (AVEs), except the recent article of Kee et al. (2009), who calculated trade restrictiveness indices in a novel way for a sample of 78 countries (including MENA Arab countries). However, this research is based on the old TRAINS database on NTMs

\footnotetext{
In some parts of the study Turkey is added to the analysis, which is a MENA country but non-Arab.
} 
which is out of date. Even more limited research is available for trade restrictiveness in services. For example, Fontagné et al. (2009) attempt to provide AVEs corresponding to services for Tunisia, Turkey, and Egypt. Finally, to our knowledge, no study has yet investigated the impact of NTMs on MENA Arab countries' trade.

Given this lack of literature, this paper aims to provide new insights into the effects of NTMs in MENA Arab countries. The first contribution of this paper relates to the original calculation of AVEs and trade effects of NTMs through the use of the new World Bank Database developed by Augier and Péridy (2010) and the new UNCTAD classification of NTMs (UNCTAD, 2009). The second contribution is the development of an original empirical model with detailed trade costs. This will make it possible to provide a first assessment of the impact of NTMs, as well as other trade costs, on trade of goods and services.

This paper is organized into three sections: In the first section, a short survey of the studies undertaken on NTMs in MENA countries is presented. This section is complemented by the presentation of the new database on NTMs developed by the World Bank (2010) on five MENA Arab countries, namely Morocco, Tunisia, Egypt, Lebanon, and Syria. The second section is dedicated to the measurement of AVEs (due to NTMs) for trade in goods in MENA countries through the use of this new database. An extension will be proposed concerning the calculation of AVEs for services through the use of the new GTAP database on services.

The third section proposes an assessment of the trade impact of trade costs for MENA Arab countries through an original econometric model detailed below. This concerns goods and services. The conclusion develops the policy implications of the results.

\section{Literature Review and Data}

\section{A. Role of NTMs in MENA countries}

Several studies have, mostly indirectly, assessed the role of NTMs in MENA countries. For example, it has been argued that NTMs have played an important role in explaining the low intra-regional trade of the region (Ghoneim et al., 2011) whether the main reasons have been economic, political, or institutional. Interestingly, when tariffs 
were reduced due to multilateral commitments or the full implementation of regional agreements, the use of NTMs started to gain momentum as a device to impede trade while acting as a substitute to the high tariffs and traditional NTMs (e.g. positive and negative lists and quotas) that used to prevail.

Other studies (Konan, 2003; Abedini and Péridy, 2008; Ghoneim et al., 2011) focused on the expected benefits of deepening trade among Arab countries. In fact, such studies identified that deep integration among Arab countries (e.g. through the harmonization of standards, customs' procedures, and the adoption of effective trade facilitation measures) will result in large welfare gains for Arab countries.

There have also been a number of studies which have tackled specific MENA Arab countries and focused on the likely impact of their integration with the EU. For example, Galal and Hoekman (1997) analyzed the expected impact of the Egypt-EU Association Agreement on the Egyptian economy. These authors concluded that Egypt needs to undertake substantial domestic reforms and overcome domestic business impediments by reducing its NTMs to gain from its FTA with the EU. Galal and Lawrence (1998) analyzed the impact of the US FTAs with both Egypt and Morocco. They used a number of statistical and quantitative indicators and concluded that the US-Egypt FTA benefits Egypt whereas the US-Morocco FTA is likely to benefit only Morocco when dynamic aspects are included. These authors emphasized that domestic reforms (by reducing their NTMs) in both Egypt and Morocco are essential to maximize the benefits of their FTAs with the US. Ghoneim et al. (2007) tried to identify the impact of deep integration between Egypt and the EU on the effectiveness of the business environment and exports' performance in Egypt. They concluded that deep integration might be of benefit if the ultimate aim is to enhance exports' market access, but this is not necessarily the case if the ultimate aim is to improve the domestic business environment.

The methodologies used in the literature are either quantitative or qualitative. In this regard, some studies applied computable general equilibrium (CGEs) models to provide an ex-ante appraisal of integration between individual MENA Arab countries and the EU, e.g. Konan and Maskus (1997), Hoekman et al. (1998), Hoekman and Konan (2000), and Zaki (2010). Most of such studies suggested that the welfare gains expected from shallow integration between Arab countries and the EU are likely to be minimal, whereas such gains are expected to increase when deep integration is pursued (see Péridy and Roux (2012) for a more complete description of these studies).

Other studies applied a gravity model approach. They reached a similar conclusion, 
which is that deep integration (partially by overcoming NTMs) will yield more positive results in terms of enhancing trade relations both among MENA Arab countries themselves and between MENA Arab countries and their major trading partners, e.g. Buigues and Martinez-Mongay (2000) and Ghoneim et al. (2011).

A final stream of studies contained a survey approach. These are, for example, Zarrouk (2000), Zarrouk (2003), LAS (2004), Hoekman and Zarrouk (2009), LAS (2007), Péridy and Ghoneim (2009), LAS (2008), and Ghoneim (2009b). Those studies identified that NTMs negatively affect trade in MENA Arab countries. For example, Zarrouk (2000) identified that there exists extra charges and surcharges (para-tariffs) in almost all MENA Arab countries. These include service charges (such as custom inspection, merchandise handling or storing fees) and additional taxes (special import licence fees or stamp taxes), as well as internal taxes levied on imports (excise taxes or charges for sensitive product categories). In any case, para-tariff measures increase the costs of importation and such measures can range from 2 to $20 \%$ of the CIF value of imports. Zarrouk (2003) showed that complying with regulations and overcoming administrative barriers accounts for $8-10 \%$ of the value of trade. Conformity assessment and product standards were among the major NTMs identified. Agricultural and agroindustrial products (processed food) were among the major products affected whenever studies have delved in details of the group of products affected, which was relatively limited.

A major problem related with the literature presented above is the lack of quantitative data on NTMs. As explained before, the survey approach is based on qualitative information, such as the perception of different stakeholders, related to NTMs. In fact, the only international data available were based on TRAINS with incomplete data.

\section{B. The new World Bank database}

The World Bank has recently provided a new detailed database on NTMs in selected MENA countries, namely Morocco, Tunisia, Egypt, Lebanon, and Syria. It has been developed by Augier and Péridy (2010). This work is based on a new classification of NTMs (UNCTAD, 2009). Basically, this new classification is much more detailed that the previous one. It distinguishes 16 categories of measures: (A) Sanitary and phytosanitary measures, (B) Technical barriers to trade, (C) Pre-shipment inspection 
and other formalities, (D) Price control measures, (E) Licences, quotas, prohibitions, and other quantity control measures, (F) Charges, taxes, and other para-tariff measures, (G) Finance measures (advance payment requirement, regulation on official foreign exchange allocation, and regulations concerning terms of payment for imports), and ( $\mathrm{H})$ Anti-competitive measures. These categories also include restrictive import channels and the use of compulsory national services, (I) Trade-related investment measures (local content measure, trade balancing measures), (J) Distribution restrictions (geographical restrictions or restrictions on resellers), (K) Restriction on post-sale services, (L) Subsidies, (M) Government procurement restrictions, (N) Intellectual property, (O) Rules of origin, and (P) Export-related measures (export prohibitions, export quotas, and other export restrictions). Categories $\mathrm{J}$ to $\mathrm{O}$ are included in the classification to collect information from private sectors through surveys and web-portals.

From this new classification, the World Bank, ITC, UNCTAD, and the WTO have launched an initiative to collect and encode NTM data into the UNCTAD's classification at a very disaggregated product level (digit-10). For that purpose, a dedicated working group has been set up to collect all information on NTMs in the MENA countries mentioned above (see detailed methodology in Augier and Péridy, 2010).

Overall, more than 120,000 tariff lines with NTMs have been identified in the selected countries. A summary of these data is displayed in Figure 1 which shows the frequency of measures applied by each country on different sectors and Figure 2 which shows the frequency of different measures applied on different sectors for each country in more detail.

The figures reveal that the highest concentration of NTMs is in commodity group 0 (agriculture) and, to a lesser extent, commodity group 1 (processed food). Yet, countries have some relative peaks, for example Egypt has a high concentration of NTMs in commodity group 5 (which contains ready-made garments and textiles), Tunisia in commodity group 2 (processed food), and Morocco in commodity group 4 (rubber, wood, and plastic). The prevalence of NTMs in group 0 for all countries is in line with the literature review, which identified that a large number of NTMs is concentrated in agricultural and processed food products.

Regarding the type of NTMs, the great bulk falls into a limited number of categories. These primarily concern Technical Barriers to Trade (TBTs) which very often account for more than one-third of overall NTMs (up to 70\% in Egypt). Sanitary and Phyto Sanitary measures(SPS) is also a major category, which accounts for up to $54 \%$ of 
overall measures in Tunisia. Export-related measures and/or charges, taxes, and other para-tariff measures are also significant, especially in Syria. The other NTM categories are generally much less applied by MENA countries.

Figure 1. Average Number of Non-tariff Measures in MENA Countries in each product line

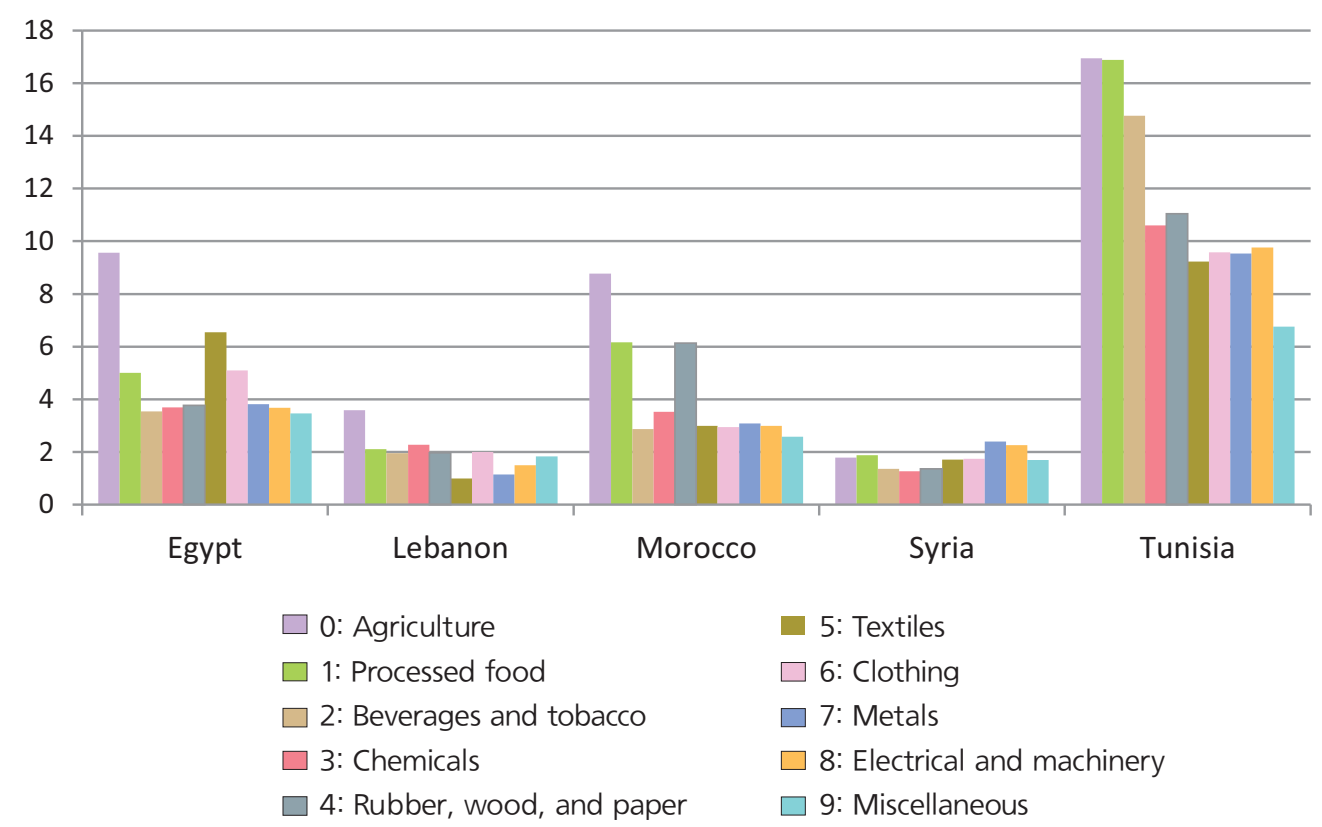

(Source) Author's calculations based on the World Bank's Non-tariff Measures Database (Augier and Péridy, 2010); 
Figure 2. Types of Non-tariff Measures in MENA Countries

(frequency measure: average number of NTM for each product line)
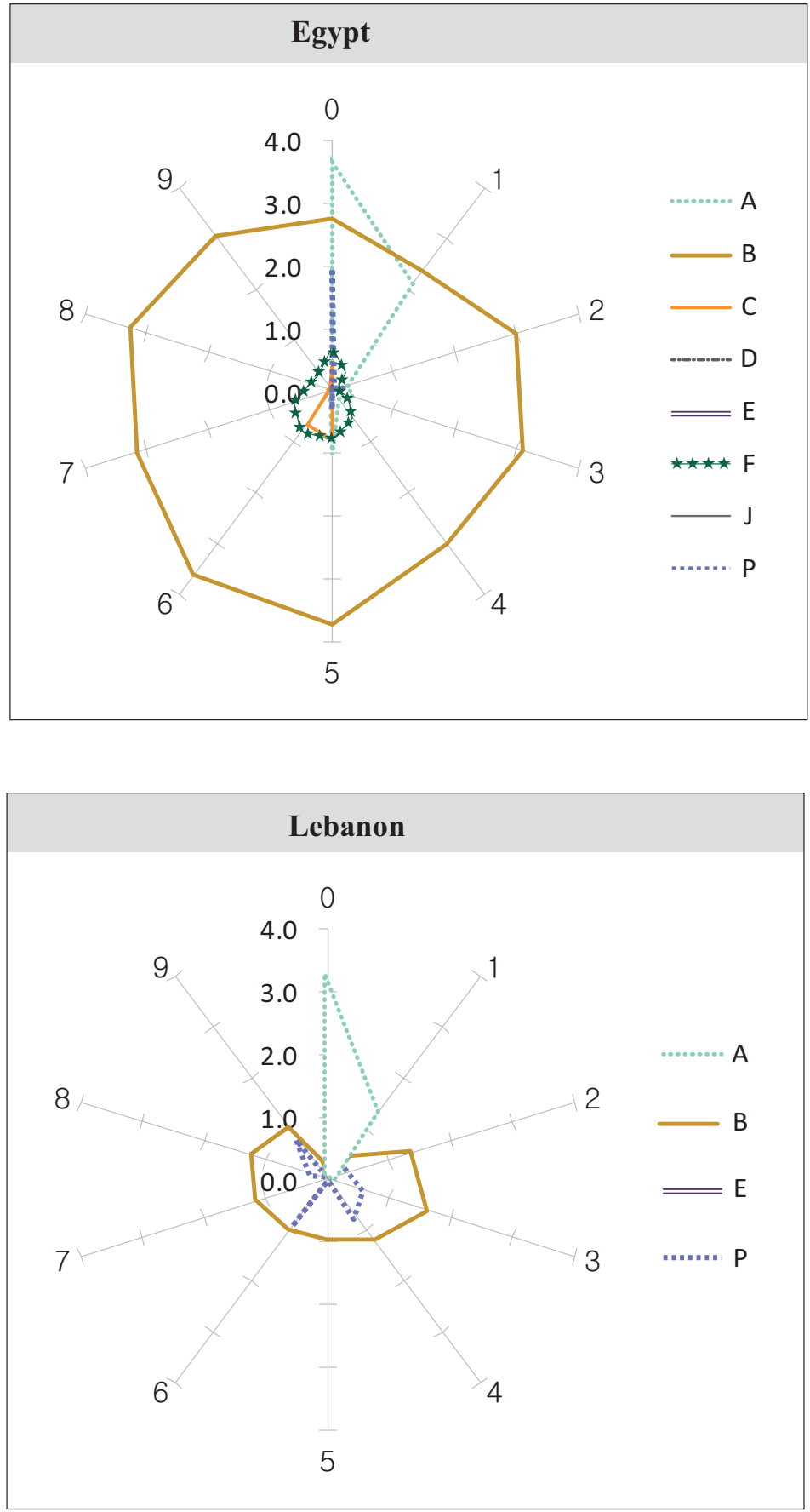

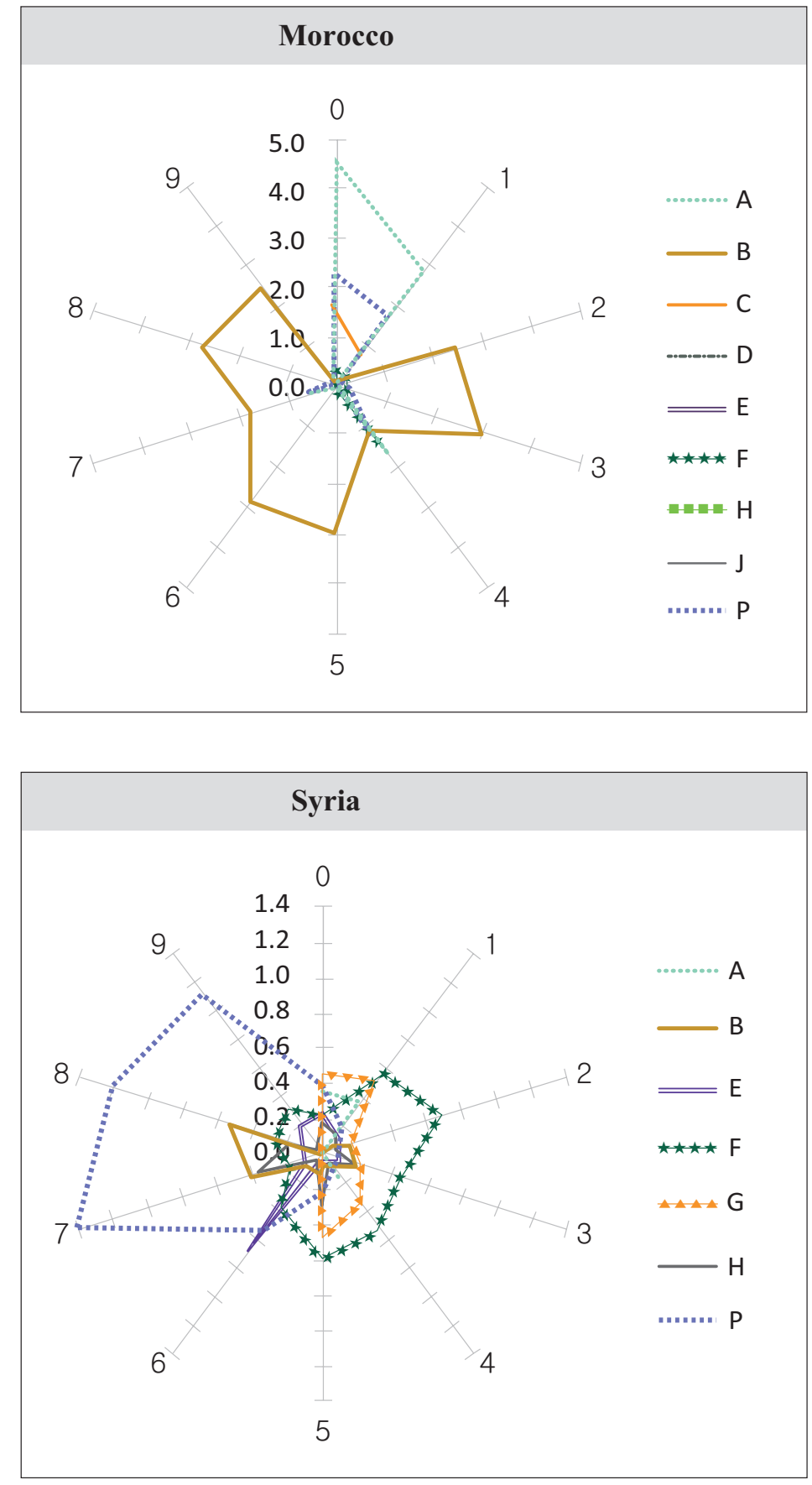


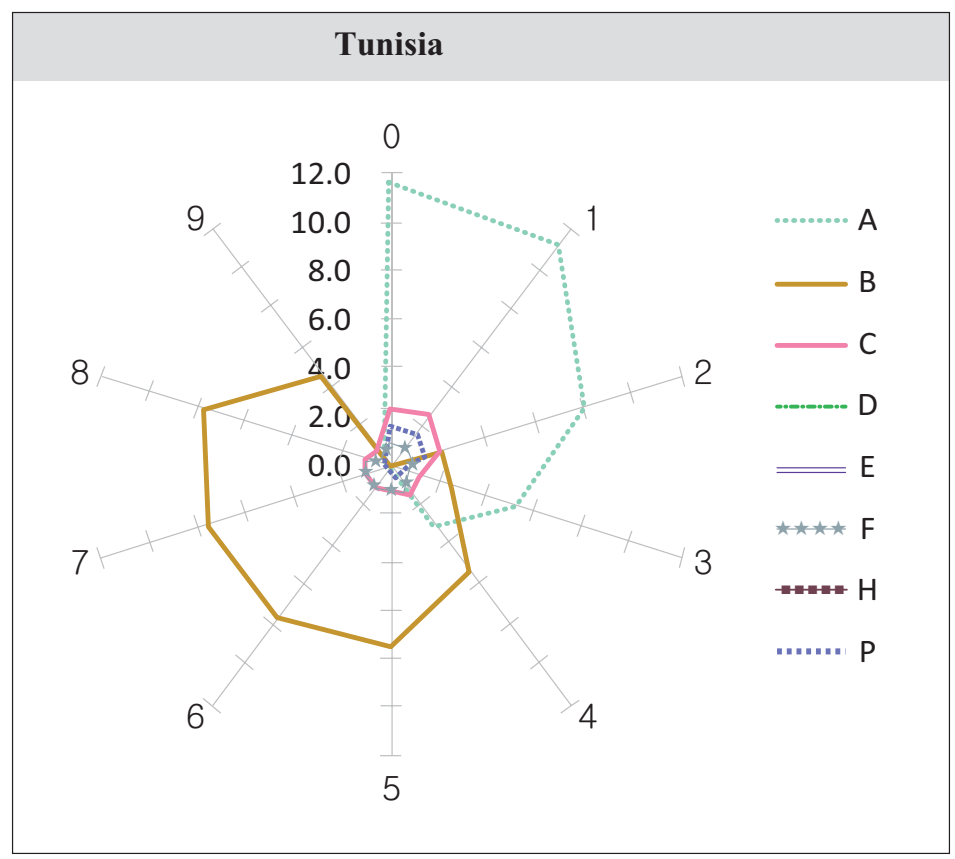

\section{Non-Tariff Measures}

A: sanitary and phytosanitary measures

B: technical barriers to trade

C: pre-shipment inspection and other formalities

D: price control measures

E: licences, quotas, prohibitions, and other quantity control measures

F: charges, taxes, and other para-tariff measures

$\mathrm{G}$ : finance measures

$\mathrm{H}$ : anti-competitive measures

I: trade-related investment measures

$\mathrm{J}$ : distribution restrictions

$\mathrm{K}$ : restriction on post-sales services

L: subsidies (excluding export subsidies under P700)

M: government procurement restrictions

$\mathrm{N}$ : intellectual property

$\mathrm{O}$ : rules of origin

P: export-related measures

(Source) Author's calculations based on World Bank Non-tariff Measures Database. 
These results lead to suspicion that NTMs are quite significant in MENA countries, especially TBTs in certain industries, such as food, textiles, and chemicals. At this stage, it must be observed that NTMs do not have solely negative effects on MENA countries. As a matter of fact, they can be a useful tool dedicated to correcting market distortions caused by free trade concerning, for instance, health and consumer security. In this regard, the progressive rise in living standard in MENA countries leads consumers to ask for more and more information, transparency, and security about the commodities they wish to buy. In this case, some NTMs provide regulations and standards aimed at protecting the consumer and increasing transparency. Another example is that NTMs can be used as a means of protecting the environment (by appropriate taxes or standards aimed at correcting the environmental damage caused by imported products). NTBs can also be used to correct distortions due to imperfect competition (for instance when imports originate from a foreign monopoly). Finally, NTMs can also produce efficiency gains, for instance when adopting common standards which lead to cost reductions and scale economies. In other words, some of the NTMs applied by MENA countries may be considered as legitimate and useful.

However, the literature review referred to above suggests that NTMs i) have increased in MENA countries, ii) have replaced parts of previous protection (tariffs), and iii) are more important than in many other countries. This can be explained by several reasons. First, some MENA countries want to protect their own industries against competitive import products, for example agriculture and food products. This protection concerns both MENA and EU partner countries. Second, MENA countries have their own national standards which are not compatible with international or EU standards. This, of course, reinforces trade barriers and the move toward the adoption of international standards or mutual recognition becomes expensive. Third, these countries experience poor administrative capacity. In this regard, the lack of training for state and local employees given the complexity of custom procedures strongly reinforce NTMs. For instance, the 2012 Doing Business survey shows that the average time which is necessary to import a commodity is equal to about 22 days in MENA countries, versus 10 days in the EU. Finally, the rules of origins lead to complex procedures (delays for getting the certificate of origin, etc.) which further reinforce NTMs in these countries.

In sum, although some NTMs may appear to be legitimate, it seems that a significant share of NTMs lead to inefficiencies and are strongly trade-reducing. This is why section 2 goes further by quantifying these NTMs in terms of AVEs (price effects), whereas section 3 will assess the trade effects of these NTMs (quantity effects). 


\section{B. Average Tariff Equivalents}

This section intends to calculate NTM tariff equivalents for trade of goods and services. They are based on new developments in the measure of trade restrictiveness, transformed into Average Equivalents(AVEs). The presentation below distinguishes two types of methods. The first is based on the Kee et al. (2009) methodology, often referred to as KNO (2009), which can be applied when data on NTMs are available, i.e. for the trade of goods. The second relies on the border effect or the fixed-effects approach, which is particularly appropriate for services for which data on NTMs are unavailable.

\section{1) Calculating AVEs for the trade of goods in MENA countries}

Concerning the estimation of AVEs related to the trade of goods, the estimations are based on the new database for five MENA countries.

Basically, the methodology selected in this sub-section primarily relies on recent techniques developed in Kee et al. (2009). This study is carried out in two stages. The first includes an estimation of the quantity impact of NTMs on imports. Then, this impact is transformed into price effects, using the import demand elasticities calculated in Kee et al. (2008). In the first stage, the basic equation to be estimated is the following:

$$
\log \left(m_{n, c}\right)=\alpha_{n}+\sum_{k} \alpha_{n, k} C_{c}^{k}+\beta_{n, c}^{n t b} n t m_{n, c}+\varepsilon_{n, c} \log \left(1+t_{n, c}\right)+\mu_{n, c}
$$

Where $m_{n, c}$ is the import value of good $n$ in country $c, C_{c}^{k}$ denotes a vector of control variables characterizing a country. These variables include relative factor endowment and GDP which capture economic size as well as other gravity variables (average distance to world market). $n t m_{n, c}$ is a dummy variable which reflects the existence of a core NTM. $t_{n, c}$ is the tariff on good $n$ in country $c$ and $\varepsilon_{n, c}$ corresponds to import demand elasticity.

Equation (1) is then modified as follows. First, import-demand elasticities estimated in Kee et al. (2008) are substituted into (1). Second, the tariff term is moved to the left-hand side to address the endogeneity of tariffs. This introduces a new error term $k_{n, c}$. Third, a White correction is introduced in order to tackle the heteroscedasticity of the error term. Fourth, product-specific effects are also introduced so as to capture the variation of $\beta$ s across tariff lines. Fifth, appropriate instrumental variables are included 
to address the endogeneity problem related to NTMs. Indeed, as shown in Lee and Swagel (1997), such endogeneity may lead to a downward bias on the estimated impact of NTMs on imports, which would result in underestimating AVEs. Sixth, a twostep estimation procedure is implemented to estimate the $\beta$ coefficients, following a Heckman two-stage procedure, while constraining $\beta$ s not to be positive.

After these transformations, the final estimated equation becomes:

$$
\log \left(m_{n, c}\right)-\varepsilon_{n, c} \log \left(1+t_{n, c}\right)=\alpha_{n}+\sum_{k} \alpha_{n, k} C_{c}^{k}+\left(-e^{\beta_{n, c}^{n b}+\sum_{k} \beta_{n, c}^{n b} C_{c}^{k}}\right) n t m_{n,+c}+\kappa_{n, c}
$$

The left-hand side of this equation reflects the value of imports once tariffs have been taken into account. This value of imports depends on country characteristics as well as on the remaining barriers to trade, i.e. NTMs and domestic support.

The last step consists of calculating the AVEs after the transformation of the quantity impact derived from equation (2) into price-equivalents. This leads to:

$$
A V E=\frac{\partial \log P^{d}}{\partial N T M}
$$

where $P^{d}$ denotes the domestic price. This equation defines AVEs as the effects of NTMs on prices. The introduction of the price variable is necessary since, like advalorem tariffs, NTM effects must be calculated on prices and not on quantities.

After the differentiation of equation (1), it is easy to obtain:

$$
A V E_{n, c}^{n t b}=\frac{e^{\beta_{n, c}^{n t b}}-1}{\varepsilon_{n, c}}
$$

In order to clarify the presentation, the results presented below focus on only the price effects (i.e. the AVEs derived from step 2), whereas the next section will present the detailed trade effects of NTMs (i.e. the quantity effects corresponding to step one).

After estimating the model, the AVEs are equal to 34\% in Tunisia, 37\% in Morocco, $39 \%$ in Egypt, and 47\% in Lebanon (Figure 3). Overall, these results are not very different from those already provided by Kee et al. (2009), except concerning Lebanon for which the AVE calculated here is much higher. This result seems to be more reliable since Lebanon has still not signed the GATT agreement. It is thus expected that its 
overall protection level (especially including NTMs) remains significant.

Ideally, it would be interesting to calculate AVEs for each product category (i.e. agriculture, foodstuffs, textiles, etc.) and each NTM category (sanitary measures, technical barriers, etc.). However, since the calculation of AVE depends on import demand elasticity and no estimation is available for this elasticity at a disaggregated level, it is preferable to calculate AVEs at the aggregated level only. However, when focusing on the quantity impact of NTMs, section $\mathrm{C}$ will make it possible to assess the trade impact of NTMs at disaggregated product and NTM category levels, since the model will not require the value of the elasticity of substitution.

In any case, these results show that NTMs correspond to a high level of protection in the selected MENA countries. Indeed, although these countries have progressively reduced their tariff levels, both in multilateral negotiation (especially since the Uruguay Round) and in the framework of regional agreement (the Barcelona and GAFTA Agreements), it seems that the remaining protection level due to NTMs remains very significant.

\section{Figure 3. Average Tariff Equivalents in selected Middle East and North African countries}

(\% in AVEs)

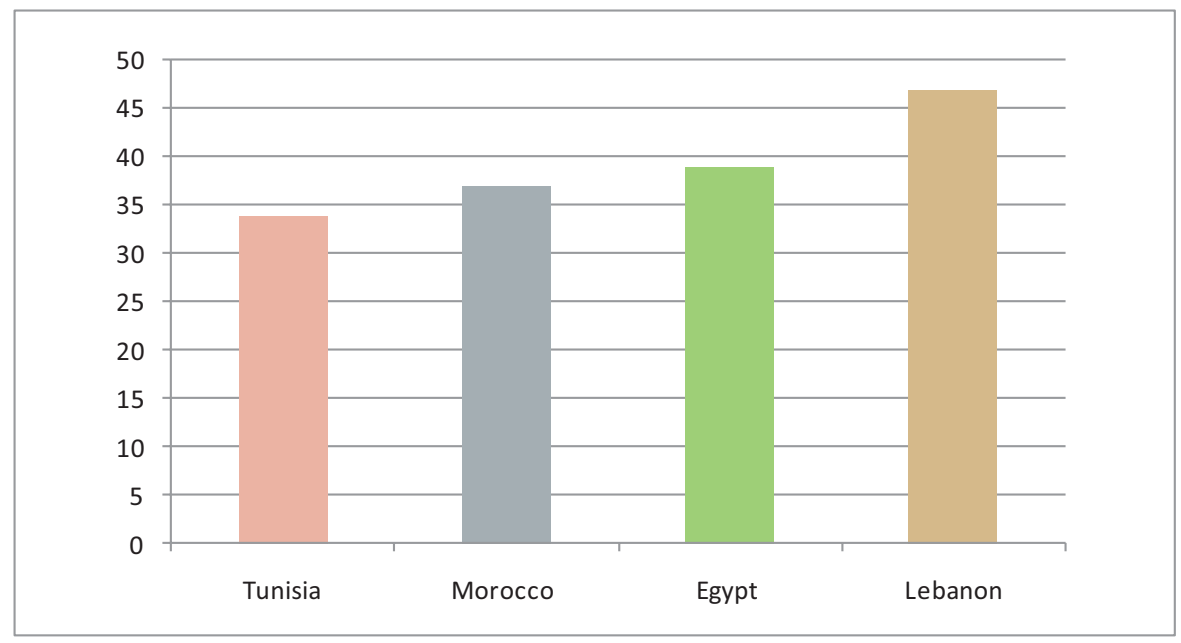

(Source) Own calculations of AVEs for NTMs. 


\section{2) The case of services}

Concerning AVEs related to services, there is a lack of data corresponding to NTMs. In order to overcome this problem, the methodology selected is based on Fontagné et al. (2009), following the initial development in Park (2002). Basically, it relies on the estimation of the fixed effects coefficients in gravity models. The advantage of this method is that it does not depend on the residuals of the model, which are likely to capture unobserved effects having nothing to do with protection. This method is also preferred to that based on import demand macroeconomic functions, which often show instability in long run parameter estimates and which do not correctly explain recent changes in imports. In addition, the standard macroeconomic import determinants barely fit the exchange of services ${ }^{2}$.

The basic equation to be estimated is the following:

$$
\ln X_{i j t}=\alpha_{0}+\alpha_{1} \log \left(Y_{i t}\right)+\alpha_{2} \log \left(Y_{j t}\right)+\alpha_{3} \log \left(D I S T_{i j}\right)+\sum_{i} \gamma_{i} I_{i}+\sum_{j} \gamma_{j} I_{j}+\sum_{t} \gamma_{t} I_{t}+\sum \alpha_{i j} D_{i j}+\varepsilon_{i j}
$$

Where $X_{i j t}$ denotes the exports of services from country $i$ to country $j ; Y_{i t}$ and $Y_{j t}$ correspond to the GDP in countries $i$ and $j$ respectively; DIST $T_{i j}$ reflects the distance between $i$ and $j$ and $D_{i j}$ is a vector of bilateral control variables (dummies), which account for common languages and Preferential Trading Areas (PTAs). Finally, $I_{i}$ and $I_{j}$ are country-specific effects, which control for the remaining country characteristics. Concerning the importing country, $I_{j}$ is supposed to essentially reflect protection, provided that the other variables have been properly included in the vector $D_{i j}$. This equation is very close to that proposed in the new gravity theoretical approach (Anderson and van Wincoop, 2003) which introduces multilateral trade resistance in countries' specific effects.

The estimation of this equation can be made in cross-section or panel data, depending on the dataset selected for our study. The dataset is derived from GTAP (updated version of November 2011): version 7.4 and includes 82 countries and 16 services sectors for the year $2007^{3}$.

Since the parameters corresponding to GDP cannot be estimated, it may be proceeded as follows. First, country $i$ 's GDP must be dropped from the equation. Its impact is therefore captured in the fixed effects $I_{i}$. Second, country $j$ 's GDP must not

\footnotetext{
${ }^{2}$ For additional discussion, see Blot and Cochard (2008)

${ }^{3}$ These include air transport, business, communication, construction, dwellings, electricity, finance, gas, goods, insurance, other services, other transport, public services, sea transport, trade, and water
} 
be dropped since $I_{j}$ is expected to capture the impact of protection only. Consequently, parameter $\alpha_{2}$ can be constrained to unity or 0.8 as a sensitivity analysis. The choice of this parameter value is guided theoretically by Anderson and van Wincoop (2003), which states that GDP parameter estimates (trade-GDP elasticity) must be equal to unity $^{4}$.

The last step consists in calculating tariff equivalents from the difference between the fixed effects calculated for a given importing country $j$ and that of a benchmark country, chosen as the country with the highest fixed effect (i.e. the lowest protection) ${ }^{5}$. Hence, the calculation of AVEs is given by the following equation:

$$
\ln (1+A V E)^{-\sigma}=\mathrm{Fe \gamma}_{j}-\mathrm{Fe} \gamma_{\text {benchmark }}
$$

This requires an estimation of the consumer CES $(\sigma)$ in each sector. As in Park (2002) and Fontagné et al. (2009), this value has been chosen to be equal to 5.6.

Results are presented in Table 1. For better information, a breakdown by country and by type of services is presented. Taking the whole country sample into account, i.e. the EU, the USA, Japan, and MENA Arab countries, the AVE for services is equal to $40 \%$. Interestingly, the average for MENA Arab countries is slightly higher, i.e. $46 \%$. This AVE is also close to the AVE calculated above for goods. This means that the protection for goods due to NTMs is similar to that for services. There are, however, significant differences across countries. As a matter of fact, Mashrek countries (Jordan, Lebanon, and Syria) taken as a single country, exhibit the smallest AVE (23.5\%). Egypt and Tunisia also show below average AVE, respectively 35\% and 39\%. On the other hand, Morocco, other Maghreb countries (Algeria and Libya), and Turkey show above average AVEs: $50 \%, 58 \%$, and $73 \%$ respectively. As a comparison, the lowest AVEs found in the sample relates to Luxemburg $(9.6 \%)$. This country is very often chosen as the benchmark, since it shows the lowest protection for most service categories. Northern EU countries and Germany also show limited AVEs (generally below 35\%). On the other hand, Southern EU countries, including France, Central and Eastern European Countries(CEECs), and Japan generally show above average AVEs.

There are also significant differences across service categories. The categories which show the lowest AVEs are goods, transport (except sea transport), business,

\footnotetext{
${ }^{4}$ The underlying assumption is that all goods are tradable. However, Péridy (2005) shows that if we consider that countries $i$ and $j$ spend a fraction $\phi$ of their revenues on tradable goods and the remaining fraction (1- $\phi)$ on non-tradable, then the trade-GDP elasticity will differ from unity.

${ }^{5}$ This requires an estimation of the consumer CES in each sector. As in Park (2002), this value has been chosen to be equal to 5.6.
} 
communication, and other services. On the other hand, electricity, gas, water, finance, insurance, and sea transport exhibit the highest AVEs. MENA Arab countries generally follow this ranking with the following specificity: AVEs are much greater than the whole country sample average for business, communication, trade, sea transport, and finance whereas they are well below average for gas only.

It is difficult to compare our results with those found in other studies, first because of the lack of quantitative analysis in this field, second because the country sample and the service categories are different. In addition, the present study relies on updated data (from year 2007 to the GTAP update of November 2011). However, looking at Fontagné et al. (2009), our results present some similarities even if their study is limited to 9 service categories instead of 15 as in the present study. In particular, they find that transport is the most liberalized (they do not distinguish between sea, air, and other transport categories) with $A V E=21 \%$ and the most protected is construction $(A V E=58 \%)$. They do not provide any estimation for energy (gas and electricity). They also show a total average for AVE equal to $35 \%$ against $40 \%$ in the present study. 
Table 1. Average Tariff Equivalents for Services

$(\%)$

\begin{tabular}{|c|c|c|c|c|c|c|c|c|}
\hline & Goods & OthTransp & AirTransp & OthSer & Business & Communic & PubServ & Construct \\
\hline Luxembourg & 34.4 & 8.1 & 4.0 & 0.0 & 5.0 & 0.0 & 24.9 & 0.0 \\
\hline Latvia & 6.7 & 7.2 & 0.0 & 13.7 & 17.4 & 20.1 & 23.7 & 16.5 \\
\hline Estonia & 3.8 & 0.0 & 7.3 & 14.8 & 9.1 & 15.7 & 16.4 & 18.3 \\
\hline Bulgaria & 3.1 & 10.4 & 10.1 & 17.5 & 21.0 & 28.9 & 28.2 & 13.5 \\
\hline Ireland & 16.5 & 14.6 & 24.4 & 23.5 & 0.0 & 22.7 & 29.6 & 64.1 \\
\hline Germany & 8.0 & 8.9 & 12.6 & 16.9 & 19.3 & 28.2 & 24.8 & 16.0 \\
\hline Denmark & 21.4 & 12.0 & 4.9 & 16.2 & 19.4 & 11.5 & 19.5 & 22.1 \\
\hline Belgium & 3.9 & 3.0 & 13.7 & 19.1 & 13.6 & 15.0 & 30.5 & 41.4 \\
\hline Nethlands & 21.7 & 20.4 & 31.1 & 22.7 & 17.0 & 18.4 & 25.7 & 46.7 \\
\hline UK & 12.7 & 9.0 & 1.1 & 13.5 & 19.6 & 17.4 & 18.9 & 40.7 \\
\hline USA & 8.2 & 0.2 & 16.7 & 20.1 & 20.7 & 14.6 & 0.0 & 61.9 \\
\hline Cyprus & 7.9 & 9.3 & 11.0 & 4.9 & 29.9 & 12,2 & 22.6 & 67.6 \\
\hline Austria & 18.8 & 20.6 & 14.9 & 22.1 & 25.1 & 29.1 & 34.9 & 32.9 \\
\hline Malta & 6.9 & 16.3 & 5.5 & 13.2 & 0.4 & 22.8 & 25.4 & 84.5 \\
\hline Sweden & 10.1 & 10.4 & 20.0 & 24.3 & 8.8 & 19.5 & 29.7 & 20.6 \\
\hline Lithuania & 6.2 & 7.8 & 36.9 & 33.7 & 41.1 & 32.3 & 22.0 & 30.7 \\
\hline Finland & 11.5 & 17.2 & 29.7 & 22.9 & 12.7 & 33.1 & 33.9 & 36.9 \\
\hline Italy & 8.7 & 20.7 & 14.3 & 27.2 & 29.9 & 31.3 & 32.6 & 38.2 \\
\hline Greece & 7.2 & 15.3 & 50.9 & 25.1 & 4.6 & 37.5 & 32.6 & 55.2 \\
\hline Spain & 2.8 & 24.3 & 13.8 & 17.8 & 22.4 & 31.8 & 37.3 & 29.2 \\
\hline Hungary & 16.3 & 16.4 & 9.1 & 7.1 & 14.8 & 27.5 & 29.2 & 34.8 \\
\hline Japan & 19.9 & 30.8 & 17.2 & 18.0 & 22.8 & 40.2 & 50.0 & 16.7 \\
\hline Slovakia & 11.3 & 14.4 & 26.1 & 20.4 & 29.6 & 42.0 & 28.4 & 28.0 \\
\hline Portugal & 8.0 & 33.2 & 8.6 & 23.1 & 46.1 & 30.7 & 41.3 & 55.3 \\
\hline Romania & 2.7 & 35.0 & 33.3 & 31.2 & 23.7 & 17.9 & 38.9 & 20.9 \\
\hline Poland & 10.7 & 20.2 & 30.8 & 21.9 & 24.6 & 34.4 & 29.5 & 36.0 \\
\hline France & 11.5 & 20.2 & 19.6 & 22.7 & 35.1 & 44.3 & 34.8 & 43.9 \\
\hline CzechRep & 10.1 & 23.2 & 25.7 & 24.9 & 22.3 & 34.1 & 37.7 & 61.5 \\
\hline Slovenia & 17.3 & 22.1 & 37.4 & 26.7 & 29.2 & 35.8 & 48.3 & 36.6 \\
\hline Other Mashrek & 7.1 & 3.1 & 6.4 & 9.9 & 8.7 & 20.3 & 28.8 & 22.1 \\
\hline Egypt & 2.8 & 8.0 & 8.9 & 17.6 & 16.5 & 11.4 & 10.1 & 15.7 \\
\hline Tunisia & 9.5 & 30.2 & 17.0 & 38.1 & 56.4 & 57.2 & 34.8 & 9.3 \\
\hline Morocco & 0.0 & 30.4 & 15.0 & 40.4 & 30.1 & 49.2 & 18.4 & 106,9 \\
\hline Other Maghreb & 15.3 & 38.5 & 36.4 & 45.6 & 36.5 & 58.3 & 34.2 & 0.4 \\
\hline Turkey & 2.8 & 50.1 & 26.6 & 44.6 & 71.5 & 51.5 & 35.1 & 104.9 \\
\hline MENA average & 6.3 & 26.7 & 18.4 & 32.7 & 36.6 & 41.3 & 25.2 & 43.2 \\
\hline Total average & 10.5 & 17.5 & 18.3 & 21.8 & 23.0 & 28.5 & 28.9 & 38.0 \\
\hline
\end{tabular}

(Note) Goods $=$ Goods, OthTransp=Other transportation, AirTransp=Air transportation, OthSer=Other services, Business $=$ Business services, Communic $=$ Communication, PubServ $=$ Public services, Construct $=$ Construction, Insurance $=$ Insurance, Trade $=$ Trade, Water $=$ Water, Elect $=$ Electrical product, Sea Transp $=$ Sea transportation, Finance $=$ Finance, Gas $=$ Gas 
Table 1. Average Tariff Equivalents for Services

$(\%$, con't $)$

\begin{tabular}{|c|c|c|c|c|c|c|c|c|}
\hline & Insurance & Trade & Water & Elect & SeaTransp & Finance & Gas & Total \\
\hline Luxembourg & 4.3 & 17.5 & 37.0 & 11.1 & 38.1 & 0.0 & 0.0 & 9.6 \\
\hline Latvia & 43.7 & 32.1 & 33.4 & 26 & 41.2 & 97.9 & 76.2 & 26.2 \\
\hline Estonia & 67.1 & 41.9 & 32.0 & 269 & 14.5 & 78.7 & 87.3 & 26.3 \\
\hline Bulgaria & 33.3 & 27.7 & 36.2 & 01 & 55.2 & 90.9 & 103.7 & 29.3 \\
\hline Ireland & 0.0 & 0.0 & 36.7 & 351 & 62.1 & 56.3 & 102.9 & 29.9 \\
\hline Germany & 40.6 & 37.0 & 38.1 & 498 & 45.3 & 82.0 & 91.5 & 31.9 \\
\hline Denmark & 9.9 & 31.6 & 47.1 & 533 & 31.2 & 62.5 & 186.5 & 33.9 \\
\hline Belgium & 49.0 & 35.2 & 39.4 & 389 & 42.1 & 76.7 & 130.0 & 34.1 \\
\hline Nethlands & 49.0 & 29.1 & 46.4 & 206 & 63.6 & 105.6 & 43.6 & 34.8 \\
\hline UK & 49.6 & 44.5 & 34.4 & 576 & 41.6 & 65.7 & 140.5 & 35.1 \\
\hline USA & 27.2 & 54.5 & 36.5 & 00 & 104.4 & 64.0 & 133.9 & 35.5 \\
\hline Cyprus & 38.0 & 34.3 & 31.9 & 1413 & 25.9 & 65.8 & 92.7 & 37.0 \\
\hline Austria & 35.5 & 49.6 & 43.7 & 680 & 90.9 & 96.7 & 34.9 & 38.5 \\
\hline Malta & 23.0 & 31.6 & 37.7 & 1655 & 86.1 & 62.5 & 42.4 & 38.9 \\
\hline Sweden & 60.8 & 38.2 & 34.1 & 434 & 41.4 & 109.2 & 165.3 & 39.7 \\
\hline Lithuania & 41.1 & 52.0 & 46.4 & 15 & 83.7 & 113.9 & 9.9 & 40.1 \\
\hline Finland & 53.5 & 40.3 & 37.7 & 163 & 29.6 & 113.7 & 165.0 & 40.9 \\
\hline Italy & 51.1 & 36.1 & 50.1 & 477 & 63.1 & 113.7 & 109.4 & 42.3 \\
\hline Greece & 29.5 & 65.0 & 59.7 & 237 & 0.0 & 118.3 & 151.1 & 42.4 \\
\hline Spain & 42.5 & 52.5 & 49.0 & 508 & 74.1 & 87.6 & 140.5 & 42.4 \\
\hline Hungary & 57.6 & 43.7 & 53.2 & 493 & 81.2 & 104.9 & 186.2 & 46.1 \\
\hline Japan & 53.8 & 30.5 & 51.6 & 1061 & 24.2 & 112.3 & 142.2 & 46.4 \\
\hline Slovakia & 48.6 & 38.6 & 54.0 & 643 & 107.8 & 84.8 & 140.3 & 46.6 \\
\hline Portugal & 61.6 & 43.8 & 57.9 & 246 & 79.2 & 120.1 & 106.3 & 46.7 \\
\hline Romania & 48.2 & 65.6 & 65.6 & 746 & 80.8 & 107.8 & 115.4 & 48.1 \\
\hline Poland & 53.0 & 48.9 & 45.0 & 607 & 66.0 & 94.3 & 197.4 & 48.9 \\
\hline France & 62.4 & 48.5 & 51.7 & 746 & 54.8 & 121.1 & 131.9 & 49.1 \\
\hline CzechRep & 51.1 & 49.9 & 55.1 & 695 & 75.5 & 82.0 & 166.5 & 49.9 \\
\hline Slovenia & 83.3 & 60.9 & 65.3 & 385 & 85.9 & 138.9 & 137.1 & 54.9 \\
\hline Other Mashrek & 17.0 & 29.2 & 0.0 & 244 & 48.5 & 73.9 & 73.5 & 23.5 \\
\hline Egypt & 17.0 & 47.5 & 33.7 & 304 & 84.9 & 104.3 & 157.8 & 35.1 \\
\hline Tunisia & 46.2 & 50.9 & 58.3 & 416 & 35.4 & 123.3 & 10.4 & 38.6 \\
\hline Morocco & 62.3 & 70.4 & 52.0 & 48 & 78.5 & 167.2 & 62.3 & 49.9 \\
\hline Other Maghreb & 59.0 & 86.9 & 62.3 & 465 & 59.3 & 143.2 & 184.6 & $\mathbf{5 7 . 8}$ \\
\hline Turkey & 42.7 & 90.0 & 69.5 & 1839 & 159.7 & 124.6 & 77.5 & 73.0 \\
\hline MENA average & 40.7 & 62.5 & 51.0 & 553 & 77.7 & 122.8 & 94.4 & 46.3 \\
\hline Total average & 43.2 & 44.5 & 46.1 & 499 & 61.6 & 96.1 & 113.7 & 40.1 \\
\hline
\end{tabular}

(Note) (1) Mashrek: the region of countries to the east of Egypt and north of the Arabian Peninsular, i.e., Iraq, Palestine, Israel, Jordan, Kuwait, Lebanon, Syria.

(2) Maghreb: the region of countries to the west of Egypt, i.e., Morocco, Algeria, Tunisia, Libya, Mauritania. 


\section{The impact of trade costs for MENA countries}

This step consists of developing an appropriate bilateral trade model in order to estimate the impact of trade costs, especially that of NTMs on trade, quantity effects.

\section{1) Theoretical background}

Basically, the model specification is based on new developments of gravity models (Anderson and van Wincoop, 2003)

Starting from a product differentiation framework with a one sector economy, and assuming that consumers have CES preferences with $\sigma$ as a common elasticity, the gravity equation may be written as (see for instance Anderson and van Wincoop (2003) p. 175):

$$
X_{i j}=\frac{Y_{i} Y_{j}}{Y_{w}}\left(\frac{T_{i j}}{P_{i} P_{j}}\right)^{1-\sigma}
$$

with:

$$
\begin{aligned}
& P_{j}^{1-\sigma}=\sum_{i} P_{i}^{\sigma-1} \theta_{i} T_{i j}^{1-\sigma}, \forall j \\
& P_{i}^{1-\sigma}=\sum_{j} P_{j}^{\sigma-1} \theta_{j} T_{i j}^{1-\sigma}, \forall i
\end{aligned}
$$

where $Y_{i}, Y_{j}$, and $Y_{w}$ denote country $i$ 's GDP, country $j$ 's GDP, and world GDP respectively; $T_{i j}$ accounts for trade costs between $i$ and $j, P_{i}$ and $P_{j}$ reflect the implicit aggregate equilibrium prices, and $\theta_{i}$ and $\theta_{j}$ are country $i$ and $j$ 's income shares. The inclusion of prices is a key improvement compared to traditional gravity equation, since they reflect multilateral trade resistance. As noted by Baldwin and Taglioni (2006), a common mistake in gravity modeling is to ignore these relative prices.

Another major problem concerns the choice of the appropriate variables which capture the bilateral trade cost $T_{i j}$. This may give rise to a bias due to omitted variables. The trade cost specification proposed here accounts for this problem by introducing specific bilateral interaction effects, which capture any remaining unobserved bilateral trade resistance variables such as cultural, political, hindrance:

$$
T_{i j}=d_{i j}^{\rho} t_{i j}^{\lambda} l_{i j}^{\psi} \eta_{i j}
$$


with $d_{i j}, t_{i j}, l_{i j}$, and $\eta_{i j}$ denoting, respectively, geographical distance (as a proxy for transport costs), tariffs and non tariff measures (NTMs), and differences in languages as well as specific bilateral interaction effects. Substituting (8) into (16) leads to the final theoretical gravity equation:

$$
\begin{aligned}
\ln X_{i j}= & \left(1+\alpha_{1}\right) \ln Y_{i}+\left(1+\alpha_{2}\right) \ln Y_{j}-\left(1+\alpha_{3}\right) \ln Y_{w} \\
& +\rho(1-\sigma) \ln d_{i j}+\lambda(1-\sigma) \ln t_{i j}+\psi(1-\sigma) \ln l_{i j} \\
& +(1-\sigma) \ln \eta_{i j}-(1-\sigma) \ln P_{i}-(1-\sigma) \ln P_{j}
\end{aligned}
$$

with $\sigma>1 ; 0<\alpha_{1}, \alpha_{2}, \alpha_{3}<1$ and $\rho, \lambda, \psi>0$.

The first line of this equation refers to the traditional "mass" gravity variables, the second line includes traditional and new bilateral trade cost variables, and the last line captures multilateral trade costs.

\section{2) Model specification and data}

Based on this theoretical framework, the empirical equation to be estimated is the following.

$$
\begin{aligned}
\log X_{i j}=a_{0} & +a_{1} \log \left(Y_{i}+Y_{j}\right)+a_{2} \log G D P C A P_{i j}+a_{3} \log d_{i j}+a_{4} T A R_{i j} \\
& +a_{5} N T M_{j}+a_{6} \log L_{i j}+\gamma_{i}+\lambda_{j}+\eta_{i j}+\varepsilon_{i j t}
\end{aligned}
$$

This equation is not very different from the model used to calculate the quantity effects of NTMs in Kee et al. (2009). However, it more specifically uses the latest developments in gravity models while not directly relying on import demand elasticities in the calculation of the trade impact of NTMs.

In this equation, the GDPs are summed across countries because equation (10) is estimated for one year and for one reporting country. As a consequence, there is only one observation for the reporting country's GDP. The GDP per capita ratio is also introduced as in many other gravity equations in the case of imperfect competition (Helpman and Krugman, 1985). $T A R_{i j}$ and $N T M_{j}$ correspond respectively to tariffs and NTMs. In addition, $\gamma_{i}$ and $\lambda_{j}$ denote the price effects referred to above. In this equation, world GDP is passed on through the intercept.

Looking at the data, the variables are measured as follows. First, trade flows 
concerning goods are derived from the Comtrade database. With regard to services, we will rely on GTAP 7 which provides data for the bilateral trade of services in 2007 for 15 service sectors in 82 countries, of which most MENA countries are taken individually (especially Egypt, Turkey, Tunisia, and Morocco). In case of data unavailability for some countries with regard to services, equation (10) can be aggregated across countries, as in the previous section.

Second, NTMs are available in the new World Bank database described previously. Contrary to the previous section in which NTMs are presented as a binary variable, the measurement of NTM here takes into account the number of NTM measures which are applied for each tariff line.

Third, Tariffs are taken from the TRAINS database.

Fourth, GDP is derived from the Centre d'Etudes Prospectives et d'Informations Internationales(CEPII) database (CHELEM)

Fifth, Distance is calculated by taking into account each country's size and the spatial distribution of the economic activity within the country. The measure adopted here is close to that of Head and Mayer (2002). It is implicitly assumed that a country' size is a disc and that economic activity is evenly distributed within this disc. This latter assumption is motivated by the lack of data at a regional level for all the countries covered by this paper. These data are necessary if we wish to specify the spatial distribution of economic activity within a country.

Finally, differences in languages: $L_{i j}$ is measured by an index which reflects the probability that a randomly selected person in the country of origin speaks a different language from a person in the destination country as in Wagner et al. (2002):

$$
L_{i j}=1-\sum_{k}\left(L_{i k} \times L_{j k}\right)
$$

$L_{i k}$ and $L_{j k}$ correspond respectively to the population in countries $i$ and $j$ which speaks the language $k$, as a proportion of the overall population. This index varies from zero (if two countries speak the same language) to unity (if they speak two different languages). Data comes from the CIA (2010).

Equation (10) is estimated with the Heckman two step procedure in order to take into account zero flows and the selection bias described in the previous section. As a sensitivity analysis, the Hausman and Taylor estimator has also been implemented in order to focus on endogeneity problems. Given that the two estimations provide very similar results, Table 2 provides results with the Heckman procedure. 


\section{Table 2. Estimation results: breakdown by NTM category}

(Heckman two-step procedure)

\begin{tabular}{|c|c|c|c|c|c|}
\hline & Egypt & Morocco & Tunisia & Lebanon & Syria \\
\hline GDP per capita & $0.546^{* * *}$ & $0.051^{*}$ & $0.104 * * *$ & $0.261 * * *$ & $0.471 * * *$ \\
\hline distance & $-1.580 * * *$ & $-1.026 * * *$ & $-0.942 * * *$ & $-0.427 * * *$ & $-0.266^{* * *}$ \\
\hline sum of GDPs & $1.888 * * *$ & $0.774 * * *$ & $0.826 * * *$ & $0.748 * * *$ & $0.539 * * *$ \\
\hline constant & $-35.631 * * *$ & $-15.192 * * *$ & $-19.124 * * *$ & $-22.179 * * *$ & $-30.760 * * *$ \\
\hline tariffs & $-0.057 * * *$ & $-1.296 * * *$ & $-0.522 * * *$ & -0.005 & $-1.145^{* * *}$ \\
\hline NTMs, of which: & $-0.241 * * *$ & $-0.043 * * *$ & $-0.061 * * *$ & $-0.196 * * *$ & -0.164 \\
\hline A: SPS measures & $-0.250 * * *$ & $-0.289 * * *$ & $-0.131 * * *$ & $-0.522 * * *$ & -0.008 \\
\hline B: TBT measures & $-0.091 * *$ & -0.010 & -0.013 & $-0.099 * *$ & $-1.213 * * *$ \\
\hline C: Pre-shipment inspection & $-3.220 * * *$ & $-0.767 * * *$ & $-0.586^{* * *}$ & - & \\
\hline D: Price control measures & -0.009 & -0.008 & $-2.398^{* * *}$ & - & \\
\hline E: Quantitative restrictions & $-5.142 * * *$ & $-0.594^{* *}$ & - & $-0.949 * *$ & $-0.393 *$ \\
\hline$F:$ Charges, taxes, para-tariffs & $-1.392 * * *$ & -0.080 & $-0.509 * * *$ & - & -0.036 \\
\hline H: Anti-competitive measures & - & -0.100 & 0.041 & - & -0.059 \\
\hline J: Distributions restrictions & -0.007 & -0.199 & - & - & \\
\hline$P:$ Export related measures & -0.001 & $-0.309 * * *$ & $-1.080 * * *$ & $-1.031 * * *$ & $-0.580 * * *$ \\
\hline number of obs. & 36825 & 40859 & 33924 & 34650 & 2844 \\
\hline
\end{tabular}

(Note) *** Significant at the $1 \%$-level; ** significant at the $5 \%$-level; * significant at the $10 \%$-level; - means that parameter estimates are unavailable either because the number of observations is too small or because the variance of the variable is too small.

Results show that all parameter estimates corresponding to NTMs are significant, except for in the case of Syria, probably because of the lower quality of the database. The greatest magnitude of these parameters is recorded for Egypt and Lebanon. Looking at the breakdown by NTM categories, it is striking to observe that the greatest trade effects are recorded for SPS measures (cat.A), Quantitative restrictions (cat. E), Pre-shipment inspection (cat.C), and export related measures (cat.P). On the other hand, technical barriers to trade are trade-restricting in Egypt, Lebanon and Syria only. In Morocco and Tunisia, the parameter estimates are insignificant. In this regard, it is interesting to observe that these countries generally show a lower proportion of TBTs than the other countries, especially Egypt and Lebanon.

A comparison across countries shows that Egypt generally shows the greatest parameter estimates, especially for pre-shipment inspection, quantitative restrictions and charges, taxes, and para-tariff measures. Lebanon shows the greatest coefficient for SPS while Syria has the greatest coefficient for TBTs. 
To sum up, it clearly appears that NTMs are significantly trade-reducing in all MENA countries, especially for the most important NTMs (SPS, pre-shipment price control, quantitative restrictions, and export-related measures). One exception is TBTs, which are frequently applied in MENA countries but are not always significantly tradereducing, especially in Morocco and Tunisia. Table 3 complements the previous results by proposing a breakdown by product category.

Table 3. Estimation results: breakdown by product category

(Heckman two-steps procedure)

\begin{tabular}{|c|c|c|c|c|c|}
\hline & Egypt & Morocco & Tunisia & Lebanon & Syria \\
\hline GDP per capita & $0.546 * * *$ & $0.051 *$ & $0.104 * * *$ & $0.261 * * *$ & $0.471 * * *$ \\
\hline distance & $-1.580 * * *$ & $-1.026 * * *$ & $-0.942 * * *$ & $-0.427 * * *$ & $-0.266 * * *$ \\
\hline sum of GDPs & $1.888 * * *$ & $0.774 * * *$ & $0.826 * * *$ & $0.748 * * *$ & $0.539 * * *$ \\
\hline constant & $-35.631 * * *$ & $-15.192 * * *$ & $-19.124 * * *$ & $-22.179 * * *$ & $-30.760 * * *$ \\
\hline tariffs & $-0.057 * * *$ & $-1.296 * * *$ & $-0.522 * * *$ & -0.005 & $-1.145^{* * *}$ \\
\hline NTMs, of which: & $-0.241 * * *$ & $-0.043 * * *$ & $-0.061 * * *$ & $-0.196 * * *$ & -0.164 \\
\hline 1-15: Agriculture & 0.035 & $-0.062 * *$ & $-0.078 * * *$ & 0.052 & 0.076 \\
\hline 16-24: Foodstuff & 0.029 & -0.009 & 0.060 & -0.051 & 0.084 \\
\hline 25-27: Mineral Products & -0.213 & 0.007 & -0.064 & 0.026 & 0.044 \\
\hline 28-40: Chemical products & $-0.887 * * *$ & 0.073 & $-0.054 * * *$ & $-0.155^{*}$ & $-0.159 *$ \\
\hline 41-49: Leather-Wood & $-1.542 * * *$ & 0.031 & $-0.051 *$ & 0.209 & 0.090 \\
\hline 50-67: Textile- Wearing & 0.032 & $-0.698 *$ & -0.012 & 0.029 & $-0.586^{* *}$ \\
\hline 68-83: Stone, glass, Metal & $-0.754 * * *$ & $-0.462 * * *$ & $-0.222 * * *$ & $-0.356^{* * *}$ & $-0.397 * *$ \\
\hline 84-85: Machinery, Electrical & $-0.855 * * *$ & $-1.524 * * *$ & $-0.162 * * *$ & $-1.187 * * *$ & $-0.111 *$ \\
\hline 86-89: Transportation & -0.068 & - & 0.110 & 0.063 & -0.010 \\
\hline 90-99: Miscellaneous & 0.037 & -0.048 & 0.051 & $-0.214^{*}$ & -0.093 \\
\hline number of obs. & 36825 & 40859 & 33924 & 34650 & 2844 \\
\hline
\end{tabular}

(Note) *** Significant at the $1 \%$-level; ** significant at the $5 \%$-level; * significant at the $10 \%$-level; - means that parameter estimates are unavailable either because the number of observations is too small or because the variance of the variable is too small.

Interestingly, Table 3 shows that NTMs have a negative impact on trade for key product categories. This mainly concerns machinery, electrical, stone, glass, metal, and chemical products for which the parameter estimates are negative and significant in all countries. Some other import products are also negatively affected by NTMs but in a limited number of countries. This concerns, agriculture for Morocco and Tunisia. In this regard, It must be observed that these two countries concentrate most of their NTMs on these sectors, i.e. $42 \%$ and $44 \%$ respectively. Secondly, leather and 
wood show a negative parameter estimate for Egypt and Tunisia. Finally, textiles and clothing exhibit a significant parameter for Morocco and Syria only. On the other hand, foodstuffs, mineral products, and transportation imports do not seem to be harmed by NTMs. These products are not greatly affected by NTMs in MENA countries.

A similar exercise can also be undertaken for services. As mentioned previously, there is no existing database related to NTMs. Consequently, the impact of NTMs on trade of services can be calculated by directly using the AVEs estimated in the previous section. The equation which is estimated is the following:

$$
\begin{aligned}
\log X_{i j}=a_{0} & +a_{1} \log \left(Y_{i}+Y_{j}\right)+a_{2} \log G D P C A P_{i j}+a_{3} \log d_{i j}+a_{4} A V E_{j} \\
& +a_{4}^{\prime} A V E_{j} * M E D_{j}+\alpha_{5} L_{i j}+a_{6} \log C O L_{i j}+\gamma_{i}+\lambda_{j}+\eta_{i j}+\varepsilon_{i j t}
\end{aligned}
$$

This is similar to equation (10) estimated for trade of commodities, except the tariff variable (excluded here), the variable $C O L_{i j}$ which measures the colonial link between countries $i$ and $j$ (included here), and the measurement of NTMs, as explained above. In addition, since the model can be estimated for the full country sample (including the EU, MENA countries, the USA, and Japan) as importing countries, a specific variable $A V E^{*} M E D_{j}$ is introduced in order to capture the specific effect of AVEs for each MENA country. Consequently, $\alpha_{4}$ measures the effect of NTMs in services for all importing countries, whereas $\alpha_{4}^{\prime}$ shows to what extent this effect is greater or lower for each MENA country. $M E D_{j}$ is a dummy variable which is equal to 1 for Mediterranean countries and 0 elsewhere. Thus, $\alpha_{4}+\alpha_{4}^{\prime}$ measures the global trade effect of NTMs for each MENA country.

Results are presented in Table 4. All the parameter estimates present the expected sign and are statistically significant at the $1 \%$-level, with the exception of language similarity. The impact of NTMs, proxied by AVEs, is clearly negative for the full country sample (-0.046). Besides, there are some specificity for MENA countries. As a matter of fact, Turkey, Morocco and other Maghreb countries exhibit a negative specific effect (from -0.011 to -0.003 ). This means that for these countries, the trade impact of NTMs is below average (i.e. from -0.057 for Turkey to -0.049 for Morocco). However, the specific impact is above average for Egypt and "other Mashrek" countries (respectively 0.003 and 0.005 ). Hence, the trade impact of these countries is equal to -0.043 and -0.041 respectively. Finally there is no specific impact for Tunisia, for which the trade impact is equal to the average $(-0.046)$. Basically, these results are consistent with those found in the previous section. Indeed, the countries with the highest AVEs also show the greatest negative trade impact (Turkey, Morocco, and other Maghreb 
countries), whereas the countries with the lowest AVEs (Egypt and other Mashrek countries) exhibit the smallest negative trade impact.

Table 4. Estimation result for services: breakdown by country

\begin{tabular}{|c|c|c|c|c|c|c|c|}
\hline GDP per capita & $0.514 * * *$ & $0.515^{* * *}$ & $0.516 * * *$ & $0.514 * * *$ & $0.507 * * *$ & $0.515 * * *$ & $0.515 * * *$ \\
\hline Distance & $-0.980 * * *$ & $-0.978 * * *$ & $-1.001 * * *$ & $-0.982 * * *$ & $-0.999 * * *$ & $-0.987 * * *$ & $-0.981 * * *$ \\
\hline Sum of GDPs & $1.204 * * *$ & $1.203 * * *$ & $1.215 * * *$ & $1.209 * * *$ & $1.203 * * *$ & $1.209 * * *$ & $1.205 * * *$ \\
\hline Language & 0.079 & 0.084 & 0.048 & 0.075 & 0.108 & 0.061 & 0.078 \\
\hline Regional agreements & $0.175^{* *}$ & $0.177 * *$ & $0.158 * *$ & $0.181 * *$ & $0.125^{*}$ & $0.182 * *$ & $0.173 * *$ \\
\hline Colony & $0.392 * * *$ & $0.392 * * *$ & $0.399 * * *$ & $0.391 * * *$ & $0.278 * * *$ & $0.394 * * *$ & $0.392 * * *$ \\
\hline AVEs & $-0.046 * * *$ & $-0.046 * * *$ & $-0.046 * * *$ & $-0.046 * * *$ & $-0.046 * * *$ & $-0.046 * * *$ & $-0.046 * * *$ \\
\hline$A V E^{*}$ Egypt & & $0.003 * * *$ & & & & & \\
\hline AVE ${ }^{*}$ Morocco & & & $-0.003 * * *$ & & & & \\
\hline AVE*Tunisia & & & & 0.001 & & & \\
\hline AVE*Turkey & & & & & $-0.011 * * *$ & & \\
\hline$A V E^{*}$ othermaghreb & & & & & & $-0.005 * * *$ & \\
\hline AVE* othermashrek & & & & & & & $0.005 * * *$ \\
\hline constant & $-5.604 * * *$ & $-5.614 * * *$ & $-5.441 * * *$ & $-5.661 * * *$ & $-5.583 * * *$ & $-5.617 * * *$ & $-5.596 * * *$ \\
\hline number of obs. & 17647 & 17647 & 17647 & 17647 & 17647 & 17647 & 17647 \\
\hline
\end{tabular}

(Note) (1) Mashrek: the region of countries to the east of Egypt and north of the Arabian Peninsular, i.e., Iraq, Palestine, Israel, Jordan, Kuwait, Lebanon, Syria.

(2) Maghreb: the region of countries to the west of Egypt, i.e., Morocco, Algeria, Tunisia, Libya, Mauritania.

Table 5 complements these results by showing a breakdown by product category. Column (1) shows the parameter corresponding to AVEs for all service categories. Then, column (2) exhibits the specific effects by category. For that purpose, $\mathrm{AVE}^{*} \mathrm{MED}_{j}$ is replaced by $\mathrm{AVE}^{*} \mathrm{CAT}_{j}$ in equation (11) where $\mathrm{CAT}_{j}$ corresponds to each service category. It is a dummy variable which is equal to 1 for one given service sector and 0 elsewhere. Column (3) indicates the sum of column (1) and (2). It thus accounts for the trade effect of NTMs for each service sector. 
Table 5. Parameter estimates for AVE: breakdown by service category

\begin{tabular}{lcrr}
\hline & AVE all services & AVE specific & AVE total \\
\hline Air Transportation & $-0.046^{* * *}$ & $0.012^{* * *}$ & $-0.034^{* * *}$ \\
Business Services & $-0.046^{* * *}$ & $0.049^{* * *}$ & 0.003 \\
Communication & $-0.046^{* * *}$ & $0.008^{* * *}$ & $-0.038^{* * *}$ \\
Construction & $-0.046^{* * *}$ & $-0.005^{* * *}$ & $-0.051^{* * *}$ \\
Electrical product & $-0.044^{* * *}$ & $-0.019^{* * *}$ & $-0.063^{* * *}$ \\
Finance & $-0.059^{* * *}$ & $-0.009 * * *$ & $-0.068^{* * *}$ \\
Gas & $-0.027^{* * *}$ & $-0.041^{* * *}$ & $-0.068^{* * *}$ \\
Goods & $-0.043^{* * *}$ & $0.047^{* * *}$ & 0.004 \\
Insurance & $-0.046^{* * *}$ & 0.001 & $-0.046^{* * *}$ \\
Other services & $-0.046^{* * *}$ & $0.008^{* * *}$ & $-0.038^{* * *}$ \\
Other Transportation & $-0.046^{* * *}$ & $0.026^{* * *}$ & $-0.020^{* * *}$ \\
Public Services & $-0.047^{* * *}$ & $-0.011^{* * *}$ & $-0.058^{* * *}$ \\
Sea Transportation & $-0.047^{* * *}$ & $-0.009^{* * *}$ & $-0.056^{* * *}$ \\
Trade & $-0.047^{* * *}$ & $0.011^{* * *}$ & $-0.036^{* * *}$ \\
Water & $-0.049^{* * *}$ & $-0.021^{* * *}$ & $-0.070^{* * *}$ \\
Total & $-0.046^{* * *}$ & 0 & $-0.046^{* * *}$ \\
\hline
\end{tabular}

(Note) $* * *$ : significant at the $1 \%$-level.

Results show that the most liberalized service categories are goods, business services, air transportation and other transportation, and communication. This finding is consistent with the results found in the previous section, which suggested that these sectors exhibit the lowest AVE. On the other hand, gas, electricity, water, finance, insurance, and public services are the service sectors with the highest AVE and thus the most negative trade impact.

\section{Policy Implications}

This paper shows that protection due to NTMs still remains in the selected MENA countries such as Morocco, Tunisia, Egypt, Lebanon, and Syria. Using the new World Bank database on detailed NTMs in five MENA countries, it has been shown that AVEs range between 34\% in Tunisia and $47 \%$ in Lebanon in terms of tariff equivalents (AVEs).

A detailed analysis on NTMs shows that almost all NTM categories are trade reducing, especially SPS measures, quantitative restrictions, pre-shipment inspection, 
and export-related measures with technical barriers to trade to a lesser extent.

Finally, it has been shown that a great number of import product categories are negatively affected by NTMs, especially machinery and electrical, stone, glass, metal, and chemical products. Agriculture, leather, wood, and textile/clothing imports are also harmed by NTMs, although not in all the selected countries.

The policy implications of these results are as follows. First, if the objective of the governments in MENA countries is to further integrate into the world economy so as to grasp additional trade gains, then these governments must consider progressing toward reduction in NTMs. Not all NTMs must necessarily be reduced or removed, but the ones which are trade-reducing must be treated with particular attention. In addition, these governments should also progress toward either mutual recognition, or the adoption of international standards.

Received 14 December 2012, Revised 12 July 2013, Accepted 25 August 2013

\section{References}

Abedini, J. and N. Péridy (2008) "The Greater Arab Free Trade Area (GAFTA): An Estimation of Trade Effects, Journal of Economic Integration, 23(4): 848-872.

Anderson J. and E. van Wincoop (2003) "Gravity with Gravitas: A Solution to the Border Puzzle", American Economic Review, 69(1):170-192

Augier, P. and N. Péridy (2010) "The Inventory of NTMs in MENA Countries", World Bank Report, International Trade Department.

Baldwin, R. and Krugman, P. (1989), 'Persistent Trade Effects of Exchange Rate Shocks', Quarterly Journal of Economics, 104, 635-654.

Baldwin, R. and D. Taglioni (2006) “Gravity for Dummies and Dummies for Gravity Equations”, National Bureau of Economic Research, Inc, NBER Working Papers: 12516

Blot, C. and M. Cochar (2008) “L'énigme des exportations revisitée: Que faut-il retenir des données de panel? ”, Revue de L'OFCE, $106: 67-100$

Buigues, P. and C. Martinez-Mongay (2000), “Trade Resistance and Global Competiveness: The Cases of Egypt, Jordan, Morocco, and Tunisia”, paper presented at the ERF 7th Annual Conference, Amman 26-29 October, 2000.

Carrère, C. and J. de Melo (2009) "Non Tariff Measures: What Do we Know, What should be Done?” Working Paper, CERDI n ${ }^{\circ}$ E-2009.33

CIA (2010) The World Factbook, Central Intelligence Agency.

Fontagné, L., A. Guillin and C. Mitaritonna (2009) "Estimations of Tariff Equivalents for the Service Sector", 
DG Trade Report, ATLASS.

Galal, A. and B. Hoekman (1997), "Egypt and the Partnership Agreement with the EU: The Road Ahead to Maximum Benefits", in A. Galal and B. Hoekman (eds.), Regional Partners in Global Markets: Limits and Possibilities of the Euro-Med Agreements, Cairo and London: ECES and CEPR.

Galal, A. and R. Lawrence (1998), "Egypt-US and Morocco-US Free Trade Agreements", in A. Galal and R. Lawrence (eds.), Building Bridges: An Egypt-US Free Trade Agreement, Cairo and Washington D.C.: ECES and Brookings Institution.

Ghoneim, A., M. El Garf, M. Gasiorek, and P. Holmes) (2007) "Examining the Deep Integration Aspects of the EU-South Mediterranean Countries: Comparing the Barcelona Process and Neighbourhood Policy, the Case of Egypt", FEMISE Project No. FEM31-08, financed by European Commission.

Ghoneim, A. F. (2009), "Regional Report on NTBs and SPS Measures facing Agricultural intra-Arab Trade", based on National Reports from Egypt, Morocco, Tunisia, Jordan, and Syria. Report submitted to World Bank Institute.

Ghoneim, A. F., J. L. Gonzalez, M. Mendez Para, and N. Péridy (2011), “ Shallow versus Deep Integration between Mediterranean Countries and the EU and within the Mediterranean Region", CASE Netowork Report No. 96/2011, Warsaw: CASE, available at http://www.case.com.pl/strona--ID-publikacje_recent,publikacja_id34038844,nlang-710.html

Head, K. and T. Mayer (2002) «Effet Frontière, Intégration Economique et Forteresse Europe», Economie et Prévision, 0: 71-92.

Helpman, E. and P.R. Krugman (1985) Market Structure and Foreign Trade: Increasing Returns, Imperfect Competition and the International Economy, Cambridge, Mass.: MIT Press.

Hoekman, B., D. Konan and K. Maskus (1998), “An Egypt-US Free Trade Agreement: Economic Incentives and Effects", in A. Galal and R. Lawrence (eds.), Building Bridges: An Egypt-US Free Trade Agreement, Cairo and Washington D.C.: ECES and Brookings Institution.

Hoekman, B. and D. Konan (2000), "Rents, Red Tape, and Regionalism: Economic Effects of Deeper Integration", in J. Zarrouk and B. Hoekman (eds.), Caching Up with the Competition: Trade Opportunities and Challenges for Arab Countries, University of Michigan Press.

Hoekman, B. and J. Zarrouk (2009), "Changes in the Cross-Border Trade Costs in the Pan Arab Free Trade Area, 2001-2008”, World Bank Policy Research Paper No. 5031, Washington D.C.: World Bank.

Kee, H., A. Nicita and M.Olarreaga (2008) “Import Demand Elasticities and Trade Distortions", The Review of Economics and Statistics, 90(4): 666-682.

Kee, H., A. Nicita and M.Olarreaga (2009) "Estimating Trade Restrictiveness Indices", Economic Journal, 119(534): 172-199.

Konan, D. (2003) “Alternative paths to prosperity: Economic integration among Arab countries", in A. Galal and B. Hoekman (eds), Arab Economic Integration: Between Hope and Reality, Cairo and Washington D.C.: Egyptian Center for Economic Studies and Brookings Institution Press.

Konan, D. and K. Maskus (1997), “A Computable General Equilibrium Analysis of Egyptian Trade Liberalization Scenarios”, in A. Galal and B. Hoekman (eds.), Regional Partners in Global Markets: Limits and Possibilities of the Euro-Med Agreements, Cairo and London: ECES and CEPR.

League of Arab States (LAS) (2007), unpublished reports on GAFTA related meetings and their minutes. 
League of Arab States (LAS) (2008), The Unified Arab Report, Cairo: LAN

Lee, J. and P. Swagel (1997) "Trade Barriers and Trade Flows across Countries and Industries", Review of Economics and Statistics, 79(3): 337-68.

Park, S. (2002) "Measuring Tariff Equivalents in Cross-Border Trade in Services", Trade working paper 353, East Asian Bureau of Economic Research

Péridy, N. (2005) "Towards a Pan-Arab free trade area: Assessing Trade Potential Effects of the Agadir Agreement", The Developing Economies, 43(3): 329-345.

Péridy, N. and A. Ghoneim (2009) "Regional Integration, Imperfect Competition and Welfare: The Experience of the Greater Arab Free Trade Area", Economie Appliquée, 52(4): 131-156.

Péridy, N. and N. Roux (2012) "Why are the Trade Gains from the Euro-Mediterranean Partnership so Small?", Journal of World Trade, 46(3): 571-596

UNCTAD (2009) "Updated classification of Non Tariff Measures", Report to the Secretary-General of UNCTAD, December 2009.

Wagner, D., K. Head and J. Ries (2002) "Immigration and the trade of provinces" Scottish Journal of Political Economy 49(5): 507-525

Zaki, C. (2010) "Trade Facilitation and Corruption: A CGE Model of Egypt", The African Development Review, forthcoming.

Zarrouk, J. (2000),"Para-Tariff Measures in Arab Countries", in H. Kheir-El-Din and B. Hoekman (eds.), Trade Policy Developments in the Middle East and North Africa, Cairo: ERF.

Zarrouk, J. (2003), “A Survey of Barriers to Trade and Investment in Arab Countries", in A. Galal and B. Hoekman (eds.), Arab Economic Integration Between Hope and Reality, Cairo and Washington D.C.: Egyptian Center for Economic Studies and Brookings Institution Press. 